\title{
Propriedades físico-químicas do amido de aveia da variedade brasileira IAC 7
}

\author{
Physicochemical properties of IAC 7 oat starch from Brazilian cultivars
}

\author{
Melicia Cintia GALDEANO ${ }^{1 *}$, Maria Victória Eiras GROSSMANN${ }^{1}$, Suzana MALI ${ }^{2}$, Luis Arturo BELLO-PEREZ ${ }^{3}$
}

\begin{abstract}
Resumo
Este estudo caracterizou o amido de aveia da variedade IAC-7 quanto às suas características químicas, reológicas, funcionais e térmicas. O amido de aveia apresentou 1,36\% de lipídios, 32,23\% de amilose e baixa capacidade retrogradante (9,19\% após 30 dias de armazenagem). Embora o amido de aveia tenha apresentado alto teor de amilose, sua baixa retrogradação pode ser devida à presença dos lipídios que, por impedimento estérico, dificultariam a reaproximação das cadeias poliméricas. O comportamento reológico das pastas de amido de aveia foi caracterizado como sendo pseudoplático. A baixa temperatura de gelatinização $\left(64,71^{\circ} \mathrm{C}\right)$ do amido de aveia também pode estar relacionada ao maior teor de lipídio deste amido.
\end{abstract}

Palavras-chave: viscosidade; reologia; retrogradação; $\mathrm{Tg}$.

\begin{abstract}
This study characterized the chemical, rheological, functional and thermal properties of oat starch of IAC-7 variety. The oat starch showed $1.36 \%$ of lipids, $32.23 \%$ of amylose and low retrogradation capacity ( $9.19 \%$ after 30 days of storage). Although the oat starch has presented high amylose content, its low retrogradation may be due to the presence of lipids that by steric impediment could make it difficult for the polymeric chains to approach. The rheological behavior of oat starch was characterized as pseudoplastic. The low gelatinization temperature $\left(64.71{ }^{\circ} \mathrm{C}\right)$ of the starch may be related to its higher lipid content.

Keywords: viscosity; reology; retrogradation; $\mathrm{Tg}$.
\end{abstract}

\section{Introdução}

Grão de cereal usado como alimento para humanos e animais, a aveia pertence à família Gramineae (WANG; WHITE, 1994a). Seu cultivo tem aumentado exponencialmente, principalmente devido à importância do seu papel como alimento funcional.

É um cereal de inverno amplamente cultivado nos Estados Unidos, Canadá, Alemanha, Finlândia e Austrália. Para que pudesse se adequar ao solo e ao clima brasileiros foi necessário o desenvolvimento de variedades adaptadas. Hoje se encontram variedades com alta produtividade de campo aliadas a ótimo rendimento e qualidade industrial (FRANCISCO et al., 2002).

$\mathrm{Na}$ aveia, o amido constitui cerca de $60 \%$ de matéria seca do grão. Está localizado principalmente no endosperma (HOOVER et al., 2003). Estudos conduzidos no passado encontraram consideráveis diferenças entre o amido de aveia e o amido de outros cereais. Estas diferenças têm sido atribuídas à maior quantidade de lipídio ligado, à co-lixiviação da amilose e amilopectina, ao menor comprimento de cadeia da amilose e ao menor tamanho dos grânulos do amido de aveia (MUA; JACKSON, 1995; WANG; WHITE, 1994a, b, c).
O lipídio presente no amido de aveia também pode ser responsável pela baixa retrogradação deste amido (ZHOU et al., 1998). Isto porque, os lipídios, por impedimento estérico, dificultam a reassociação das cadeias poliméricas durante o resfriamento da pasta (WANG; WHITE, 1994c).

No entanto, amidos de diferentes cultivares de aveia têm mostrado diferentes propriedades físico-químicas (WANG; WHITE, 1994a, b; ZHOU et al., 1998; HOOVER et al., 2003). Todos os estudos sobre amido de aveia foram conduzidos com cultivares americanas, australianas e canadenses. Não se tem relatos de caracterização do amido de aveia de cultivares brasileiras. Portanto este estudo propôs caracterizar o amido de aveia da variedade IAC-7 (cultivar brasileira) quanto às suas características químicas, reológicas, funcionais e térmicas.

\section{Material e métodos}

\subsection{Material}

$\mathrm{O}$ amido de aveia (cultivar IAC-7) foi extraído a partir da farinha de aveia fornecida pela SL Alimentos (Brasil), de

Recebido para publicação em 5/3/2008

Aceito para publicação em 3/7/2008 (003279)

${ }^{1}$ Departamento de Ciência e Tecnologia de Alimentos, Centro de Ciências Agrarias - CCA, Universidade Estadual de Londrina - UEL, CP 6001, CEP 86051-990,

Londrina - PR, Brasil, E-mail: melicia@slalimentos.com.br

${ }^{2}$ Departamento de Bioquímica e Biotecnologia, Centro de Ciências Exatas - CCE, Universidade Estadual de Londrina, CP 6001, CEP 86051-990, Londrina - PR, Brasil

${ }_{3}^{3}$ Centro de Desarrollo de Productos Bióticos - CEPROBI, Instituto Politécnico Nacional, CP 62731, Yautepec-MO, México

${ }^{*}$ A quem a correspondência deve ser enviada 
acordo com Lim et al. (1992). Cem gramas de farinha foram misturadas com $300 \mathrm{~mL}$ de $\mathrm{NaOH} 0,08 \mathrm{M}$ e deixados em repouso por 1 hora. Centrifugou-se a $3500 \mathrm{rpm} / 10$ minutos descartando o sobrenadante (HERAEUS CRYOFUGE 6000i, Alemanha). As camadas superiores do precipitado foram removidas por raspagem. $\mathrm{O}$ precipitado foi ressuspendido em água destilada, repetindo-se a centrifugação e raspagem das camadas superiores, até que a dispersão apresentasse coloração branca. $\mathrm{O}$ precipitado foi seco em estufa a $40{ }^{\circ} \mathrm{C}$ até que atingisse $11 \%$ de umidade.

\subsection{Caracterização do amido}

\section{Composição química}

Umidade, proteína e cinzas foram determinadas de acordo com os métodos da AACC (1990). Os lipídios foram determinados através de hidrólise ácida, de acordo com Vasanthan e Hoover (1992).

O teor de amilose foi determinado de acordo com Jarvis e Walker (1993) e Landers, Gbur e Sharp (1991). Foi realizado um desengorduramento prévio da amostra com metanol a frio. Cem miligramas de amido (bs) foram misturados com $1 \mathrm{~mL}$ de etanol a $95 \%$ e $9 \mathrm{~mL}$ de $\mathrm{NaOH} 1 \mathrm{~N}$ e deixados solubilizar, por 24 horas, sob temperatura ambiente com agitação ocasional. Em seguida, as amostras foram colocadas em balão volumétrico $(100 \mathrm{~mL}) \mathrm{e}$ foi completado o volume com água destilada. Transferiu-se uma alíquota de $5 \mathrm{~mL}$ para outro balão de $100 \mathrm{~mL}$, neutralizou-se com $1 \mathrm{~mL}$ de solução de ácido acético $1 \mathrm{~N}$, adicionaram-se $2 \mathrm{~mL}$ de reagente de cor ( $0,2 \mathrm{~g}$ de iodo e $2 \mathrm{~g}$ de iodeto de potássio), completando-se o volume com água destilada. Foram feitas leituras das absorvâncias nos comprimentos de onda 504, 548, $560,580,620,630,700$ e $720 \mathrm{~nm}$.

\section{Propriedades de pasta}

Uma dispersão de 6\% de sólidos (bs) foi levada ao viscógrafo Brabender Pt 100 (Alemanha) para aquecer de 30 a $95^{\circ} \mathrm{C}$ a uma velocidade de $1,5{ }^{\circ} \mathrm{C} /$ minutos. A amostra foi mantida por 20 minutos a $95{ }^{\circ} \mathrm{C}$ e, em seguida, iniciou-se a etapa de resfriamento até $50{ }^{\circ} \mathrm{C}$ a uma taxa de $1,5{ }^{\circ} \mathrm{C}$ /minutos. A velocidade de agitação foi $75 \mathrm{rpm}$.

\section{Retrogradação do gel}

Foi determinado segundo Biliaderis (1992). Suspensões de amido (6\% de sólidos (bs)) foram aquecidas em viscógrafo Brabender Pt 100 (Alemanha) a uma taxa de $3^{\circ} \mathrm{C} /$ minutos. Ao atingir $95^{\circ} \mathrm{C}$, as pastas foram pesadas em recipientes $(3 \mathrm{~cm}$ de diâmetro $\times 5 \mathrm{~cm}$ de altura) previamente tarados e, em seguida, tampadas e levadas ao refrigerador. Foi registrado o peso dos potes nos tempos 1, 2, 4, 8, 11, 18, 20, 26, 28 e 30 dias. A perda de massa após a retirada de água por exsudação foi registrada como porcentagem de retrogradação.

\section{Curvas de fluxo}

Dispersões a 5\% de sólidos foram analisadas em Reômetro TA Instruments AR 1000 (EUA), por meio de um sistema de cone e placa, ângulo de $1^{\circ}$, diâmetro de $6 \mathrm{~cm}$ e um tamanho de amostra de $1 \mathrm{~mL}$. Realizaram-se varreduras nas temperaturas de 25,95 e $40^{\circ} \mathrm{C}$, a uma taxa de aquecimento-resfriamento de $2,5^{\circ} \mathrm{C} /$ minutos, sendo que as leituras foram realizadas somente no resfriamento a $40^{\circ} \mathrm{C}$.

\section{Viscoelasticidade}

O comportamento viscoelástico foi determinado por meio da realização de provas oscilatórias em reômetro TA Instruments AR 1000 (EUA), empregando-se um sistema de cone e placa, ângulo de $4^{\circ}$, diâmetro de $6 \mathrm{~cm}$, e um tamanho de amostra de $4 \mathrm{~mL}$. Foi feita uma dispersão a $5 \%$ de sólidos e realizadas varreduras de amplitude da deformação em um intervalo de 0,1 a $10 \%$, a uma frequência constante de $10 \mathrm{~Hz}$, e uma velocidade de aquecimento-resfriamento de $2,5{ }^{\circ} \mathrm{C} /$ minutos, em um ciclo por etapas (a etapa 1 de aquecimento $\left(25\right.$ a $\left.90^{\circ} \mathrm{C}\right)$; a etapa 2 de cozimento $\left(90^{\circ} \mathrm{C}\right)$; e a etapa 3 de resfriamento $\left(90\right.$ a $\left.\left.25^{\circ} \mathrm{C}\right)\right)$, para determinar a região viscoelástica linear (RVL). As varreduras de frequência foram realizadas em um intervalo de 0,1 a $10 \mathrm{~Hz}$ a uma deformação constante de $0,3 \%$, nas temperaturas mencionadas previamente. Determinaram-se os módulos de armazenamento (G') e de perda (G') e a tangente do ângulo de defasagem $(\tan \delta)$ por meio do programa Data Analysis (TA Instruments).

\section{Propriedades térmicas}

As propriedades térmicas do amido de aveia foram estudadas utilizando-se um Calorímetro Diferencial de Varredura (DSC) modelo 2010 (TA Instrument, USA) de acordo com o método proposto por Paredes-López, Bello-Perez e Lopez (1994). Foram pesados $2 \mathrm{mg}$ de amostra (bs) dentro de uma cápsula de alumínio e adicionaram-se $7 \mu \mathrm{L}$ de água deionizada. A cápsula foi selada e deixada em repouso por 30 minutos antes da análise. Como referência, foi utilizada uma cápsula de alumínio vazia. A amostra foi submetida a um programa de aquecimento de 10 e $180^{\circ} \mathrm{C}$ a uma velocidade de $10^{\circ} \mathrm{C} /$ minutos. As temperaturas de início, de pico e final de gelatinização e as temperaturas de fusão do complexo amilose-lipídio e suas respectivas entalpias foram obtidas por meio do software TA Instruments $\mathrm{OS} / 2$ versão 2.1 .

\section{Análise estatística}

Foi utilizado o programa STATISTICA versão 5.0 (Statsoft) para análise de variância (ANOVA). Diferenças significativas $(\mathrm{p} \leq 0,05)$ foram determinadas usando o teste de Tukey.

\section{Resultados e discussão}

\subsection{Composição química}

O amido de aveia apresentou $1,36 \%$ de lipídios, $0,41 \%$ de proteína e $0,32 \%$ de cinzas. O amido de aveia, em contraste com o de outras fontes botânicas (milho 0,29\%; inhame 0,27\% e mandioca, $0,28 \%$, MALI et al., 2006), apresenta maior teor de lipídios. A maioria destes lipídios está presente no grânulo como complexo de inclusão com a amilose, uma vez que os lipídios 
não complexados são removidos no processo de extração do amido (WANG; WHITE, 1994b).

\subsection{Teor de amilose}

$\mathrm{O}$ amido de aveia apresentou 32,23\% de amilose, o que está de acordo com o teor reportado por Shamekh, Forsell e Poutanen (1994). A aveia apresentou maior teor de amilose que quinoa (7,1\%, TANG; WATANABE; MITSUNAGA, 2002), milho (28\%, CHUNG; LAI, 2005) e cevada (29,2\%, TANG; WATANABE; MITSUNAGA, 2002).

\subsection{Propriedade de pasta}

A propriedade de pasta do amido de aveia do presente trabalho e de outros estudos pode ser observada na Tabela 1. Quando se alcançou o estágio de cozimento da pasta $\left(95^{\circ} \mathrm{C}\right)$, ocorreu uma diminuição na viscosidade. Esta diminuição pode estar associada à perda da estrutura granular (SOPADE; HALLEY; JUNMING, 2004). Wang e White (1994c) também verificaram este comportamento, embora de maneira mais acentuada (redução de 190 para 80 UB).

Após 30 minutos a $95^{\circ} \mathrm{C}$, a consistência da pasta fornece uma estimativa da estabilidade ou resistência à desintegração como um resultado do aquecimento e agitação. Nestas condições, o amido de aveia, com uma redução de apenas 20 UB no final do tempo estabelecido, mostrou maior estabilidade que os de mandioca e de batata, que apresentaram reduções de 80 e 315 UB, respectivamente (CEREDA, 2003). No estágio de resfriamento $\left(50^{\circ} \mathrm{C}\right)$ foi observado um grande aumento na viscosidade (de 100 para $440 \mathrm{UB}$ ), sendo atribuído à reassociação das cadeias do amido.

MacArthur e D’Appolonia (1979), estudando três variedades de aveia, encontraram temperatura de pasta de 81 a $83,5^{\circ} \mathrm{C}$, similares às reportadas neste trabalho. Entretanto, reportaram valores de viscosidade máxima (760 a $855 \mathrm{UB}$ ) e de viscosidade no resfriamento a $50{ }^{\circ} \mathrm{C}(870$ a $1130 \mathrm{UB})$ muito superiores aos encontrados no presente trabalho. Estas diferenças podem estar relacionadas às diferentes variedades de aveia, como também, ao processo de extração do amido. Hoover e Senanayake (1996) relataram que a quantidade de componente lixiviado, o teor de lipídio amiláceo e a magnitude das forças de interação dentro do grânulo também podem originar tais variações.

\subsection{Retrogradação}

A retrogradação de pastas de amido de aveia foi acompanhada durante 30 dias a $4{ }^{\circ} \mathrm{C}$ (Figura 1). $\mathrm{O}$ amido de aveia apresentou baixa capacidade retrogradante $(9,19 \%$ de perda de massa após 30 dias de armazenagem) quando comparado à de outras fontes botânicas, como inhame e milho (45,5 e 11,5\%, respectivamente, após armazenagem por 7 dias a $4{ }^{\circ} \mathrm{C}$ ) (KARAM, 2003).

Embora o amido de aveia apresente maior teor de amilose $(32,23 \%)$ que o de milho (25\%), o de mandioca (19\%) (MALI et al., 2006) ou o de trigo (24\%) (FENNEMA, 1993), sua baixa retrogradação pode ser devida à presença dos lipídios que, por impedimento estérico, dificultariam a reaproximação das cadeias poliméricas.

Doublier, Paton e Llamas (1987) confirmaram a ação do lipídio na diminuição da capacidade retrogradante do amido de aveia, através da extração destes materiais do amido. Os autores verificaram que, após isso, o gel retrogradou rapidamente, quando armazenado a $4{ }^{\circ} \mathrm{C}$ por 48 horas. No amido nativo, nenhuma sinérese foi observada nestas condições.

Estudos com DSC também já mostraram que géis de amido de aveia são menos susceptíveis à retrogradação durante armazenagem que os de milho e cevada (SHAMEKH; FORSSEL; POUTANEN, 1994; WANG; WHITE, 1994c). Hoover et al. (1994) verificaram que as endotermas da retrogradação de amidos de trigo e de batata apareceram após três dias de armazenagem, enquanto que para o amido de aveia o tempo correspondente foi de quinze dias. Também, a função antirretrogradante dos

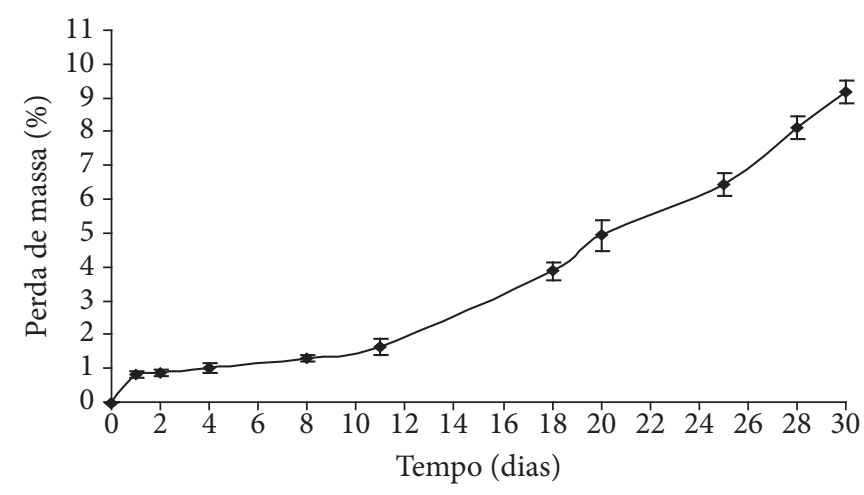

Figura 1. Perda de massa (\%) do gel de amido de aveia.

Tabela 1. Propriedade de pasta do amido de aveia.

\begin{tabular}{|c|c|c|c|c|c|}
\hline $\begin{array}{r}\text { Temperatura } \\
\text { de pasta }\left({ }^{\circ} \mathrm{C}\right)\end{array}$ & $\begin{array}{l}\text { Viscosidade } \\
\text { máxima (UB) }\end{array}$ & $\begin{array}{r}\text { Viscosidade } \\
\text { a } 95^{\circ} \mathrm{C}(\mathrm{UB}) \\
\end{array}$ & $\begin{array}{c}\text { Viscosidade após } 30 \text { minutos } \\
\text { a } 95^{\circ} \mathrm{C} \text { (UB) }\end{array}$ & $\begin{array}{l}\text { Viscosidade } \\
\text { a } 50^{\circ} \mathrm{C}(\mathrm{UB})\end{array}$ & Referência \\
\hline 81,7 & 150 & 120 & 100 & 440 & Presente trabalho ${ }^{\mathrm{a}}$ \\
\hline 89,5 & 190 & 80 & 170 & 410 & Whang e White (1994c) ${ }^{b}$ \\
\hline 95,7 & - & 139 & 112,5 & 445 & Hoover e Senanayake (1996) \\
\hline 94,7 & - & 162,5 & 117,5 & 490 & Hoover e Senanayake (1996) \\
\hline
\end{tabular}

${ }^{\mathrm{a}}$ IAC 7; ${ }^{\mathrm{b}} \mathrm{E} 77$; $\mathrm{c}$ Dal; ${ }^{\mathrm{d}} \mathrm{NO} 753-2 ; \mathrm{e}^{\mathrm{e}}$ AC Stewart. 
lipídios já foi comprovada por esta metodologia, e foi visto que a entalpia de transição de amilopectina recristalizada diminui na presença de lipídios (BILIADERIS, 1992).

A cinética de retrogradação exibe estreita dependência com a temperatura, sendo que sob temperaturas abaixo de $4{ }^{\circ} \mathrm{C}$ ocorre intensificação do fenômeno (ELIASSON, 2004). Essa alta estabilidade à retrogradação do amido de aveia sugere a aplicação deste amido como espessante em produtos congelados, sem prejudicar a qualidade final do produto.

\subsection{Curvas de fluxo}

O conhecimento das propriedades reológicas proporciona informação tecnológica, econômica e comercial, ajudando a predizer a textura e as propriedades de fluxo durante o processamento do produto (STEFFE, 1996).

A $40{ }^{\circ} \mathrm{C}$ (Figura 2), no resfriamento, a pasta de amido de aveia apresentou uma dependência da velocidade de deformação, indicando um comportamento não Newtoniano.
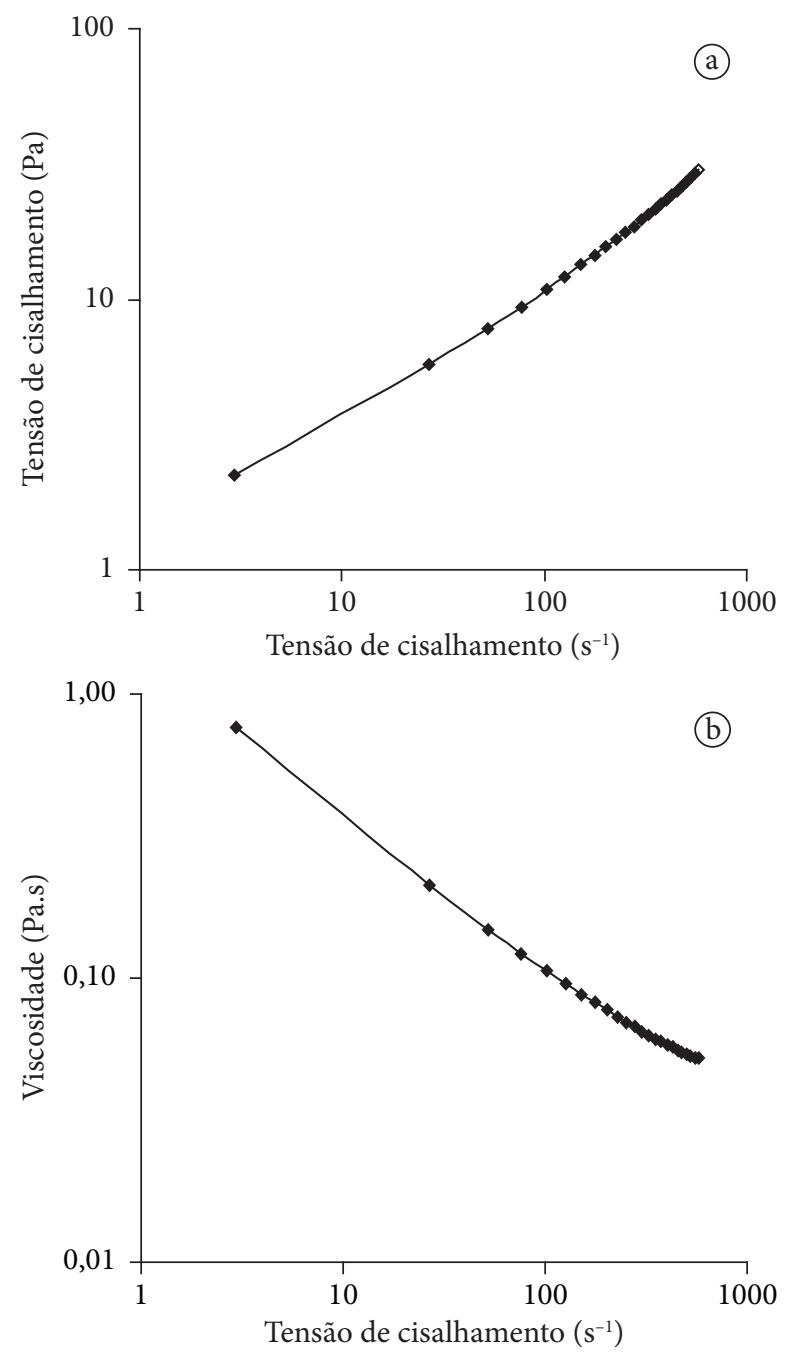

Figura 2. Curva de fluxo de pastas de amido de aveia $(5 \% \mathrm{p} / \mathrm{v})$ a $40{ }^{\circ} \mathrm{C}$, no resfriamento. a) taxa de cisalhamento versus tensão de cisalhamento; e b) taxa de cisalhamento versus viscosidade aparente.
Ao aplicar o modelo da Lei da Potência, este comportamento foi confirmado, mostrando um tipo de fluido reofluidizante ou pseudoplástico $(\mathrm{n}<1)$ (Tabela 2$)$, isto é, a viscosidade decresce com o aumento da taxa de cisalhamento.

Entretanto, este resultado não está de acordo com o reportado por Zhou et al. (1998) que estudaram variedades americanas e canadenses. Para estes autores, pastas de amido de aveia apresentam comportamento tixotrópico. Entretanto, Steffe (1996) relatou que os comportamentos reológicos das substâncias não são exclusivos, ou seja, um material pode apresentar tixotropia e reofluidização, dependendo das condições experimentais.

\subsection{Viscoelasticidade}

A varredura de deformação é utilizada para observar o comportamento do material submetido a um aumento na deformação a uma temperatura e frequência constantes, com a finalidade de determinar os limites do comportamento viscoelástico da amostra, dado que na região viscoelástica linear (RVL) as propriedades reológicas não são dependentes da deformação ou do esforço (SOPADE; HALLEY; JUNMING, 2004). Na Figura 3, observa-se que, para o amido de aveia, foi obtido a RVL entre 0,1 e $0,5 \%$ de deformação. Portanto, foi utilizado um valor de $0,3 \%$ de deformação para as varreduras de frequência.

Por ser uma dispersão diluída, os dados a $25{ }^{\circ} \mathrm{C}$, antes do aquecimento, para a varredura de frequência não foram

Tabela 2. Resultados viscosimétricos de pastas de amido de aveia, a $40^{\circ} \mathrm{C}$, no resfriamento.

\begin{tabular}{lcccc}
\hline \multicolumn{1}{c}{ Parâmetro } & Tipo de fluido & $\mathrm{R}^{2}$ & $\mathrm{n}$ & $\mathrm{k}$ \\
\hline $\begin{array}{l}\text { Tensão de } \\
\text { cisalhamento }(\tau)(\mathrm{Pa})\end{array}$ & Reofluidizante & 0,9917 & 0,5039 & 1,1156 \\
$\begin{array}{l}\text { Viscosidade } \\
\text { aparente }(\eta)(\mathrm{Pa} . \mathrm{s})\end{array}$ & Reofluidizante & 0,9911 & 0,5049 & 1,1215 \\
\hline
\end{tabular}

$\mathrm{R}^{2}$ = coeficiente de determinação; $\mathrm{n}$ = comportamento de fluxo (adimensional); $\mathrm{e}$ $\mathrm{k}=$ coeficiente de consistência (Pa.s).

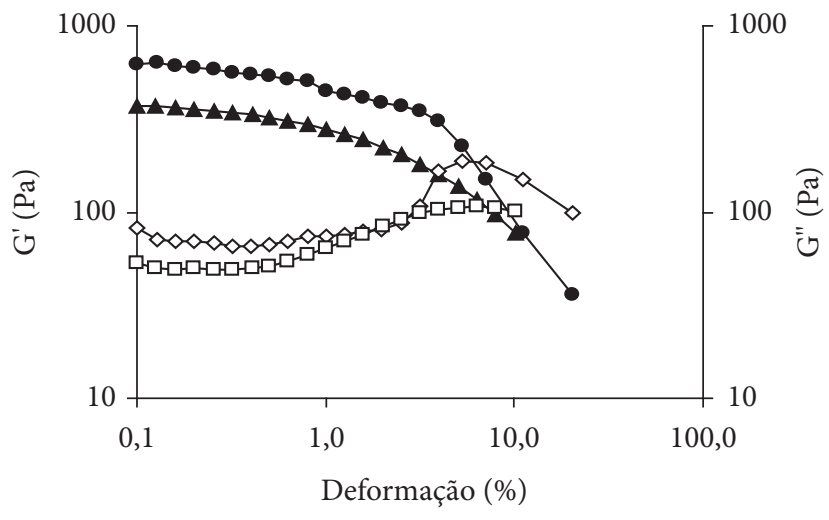

$\multimap \mathrm{G}^{\prime} 90^{\circ} \mathrm{C} \quad \multimap \mathrm{G}^{\prime} 25^{\circ} \mathrm{C} \quad \prec \mathrm{G}^{\prime \prime} 90^{\circ} \mathrm{C} \quad \neg-\mathrm{G}^{\prime \prime} 25^{\circ} \mathrm{C}$

Figura 3. Varredura de deformação de pastas de amido de aveia (5\% p/v). 
considerados. Apenas os dados a 90 e $25{ }^{\circ} \mathrm{C}$ (resfriamento) foram estudados.

A $90^{\circ} \mathrm{C}$ (Figura 4), temperatura em que se tem o inchamento dos grânulos e assim seu desordenamento, o amido de aveia mostrou maior valor do módulo de armazenagem ou elástico $\left(G^{\prime}\right)$. Este comportamento é típico para gel de amido; módulo elástico (G') maior que o módulo viscoso (G”), no qual ocorre uma resposta assemelhada, predominantemente, a um sólido (SOPADE; HALLEY; JUNMING, 2004).

O mesmo foi observado após o resfriamento, a $25{ }^{\circ} \mathrm{C}$. Durante esta etapa, observou-se o comportamento dos módulos no que se chama maturação do gel. Houve um aumento numérico dos valores dos módulos, o que pode ser devido à interação das moléculas, reforçando a estrutura do gel (ELIASSON, 2004).
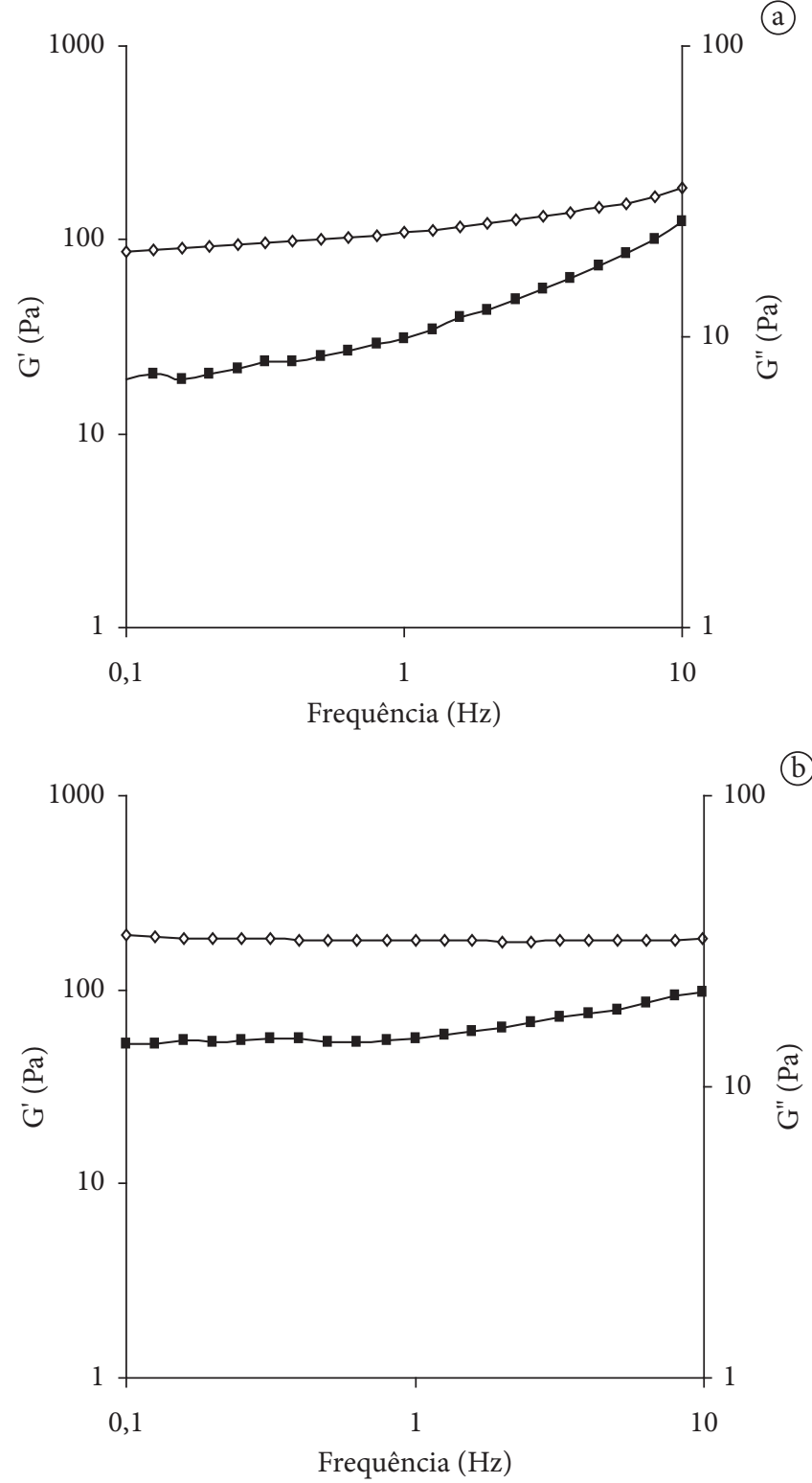

Figura 4. Valores de G' $(\bullet)$ e G”'(ם) para varredura de frequência nas pastas de amido de aveia. a) $90^{\circ} \mathrm{C}$; e b) $25^{\circ} \mathrm{C}$ (no resfriamento).
No transcurso da prova, foram obtidos valores de $\tan \delta$ entre 0,14 e 0,12 na etapa de aquecimento e de 0,11 e 0,07 no resfriamento. Com estes valores, pode-se elucidar o tipo de material que se estava analisando. No início da análise $\left(25^{\circ} \mathrm{C}\right)$, o polímero se comportou como material amorfo, com a $\tan \delta$ próxima a $0,6-0,8$. Os valores foram diminuindo ao finalizar a análise, mostrando que o material sofreu uma mudança de amorfo para vítreo, ou com regiões cristalinas, devido à retrogradação (FERRY, 1980 apud DELLA-VALLE, 2005).

\subsection{Propriedades térmicas}

Duas transições térmicas foram visualizadas através da calorimetria diferencial de varredura (DSC): uma para a fusão dos cristais $\left(\mathrm{T}_{\mathrm{m}}\right)$ e outra relacionada à fusão do complexo amilose-lipídio (Figura 5).

Os resultados das temperaturas de gelatinização $\left(64,71^{\circ} \mathrm{C}\right)$ e de fusão do complexo amilose-lipídio $\left(94,42{ }^{\circ} \mathrm{C}\right)$ estão próximos aos reportados por Hoover e Senanayake (1996). Hoover et al. (2003) reportaram temperatura de gelatinização entre 56 e $74{ }^{\circ} \mathrm{C}$ e entalpia de 12,4 a $14,6{\mathrm{~J} . g^{-1}}$ para diferentes cultivares de aveia.

Wang e White (1994c) compararam as transições dos amidos de milho e de aveia e verificaram que a temperatura de gelatinização foi menor para a aveia $\left(56\right.$ a $\left.60{ }^{\circ} \mathrm{C}\right)$ que para o milho $\left(67,6\right.$ a $\left.69,5^{\circ} \mathrm{C}\right)$. De acordo com os autores, esse baixo valor da aveia, poderia estar relacionado ao maior teor de lipídio deste amido. Relatam ainda que esta menor temperatura do amido de aveia sugere menor organização da estrutura cristalina deste amido.

Mua e Jackson (1995) também constataram que o amido de aveia apresentou menor temperatura de gelatinização $\left(65^{\circ} \mathrm{C}\right)$ que o amido de milho $\left(75^{\circ} \mathrm{C}\right)$. De acordo com Hoover et al. (2003), o amido que apresenta baixa temperatura de gelatinização e baixa entalpia de transição pode refletir a presença abundante de cadeias curtas nas ramificações da amilopectina, como é o caso do amido de aveia.

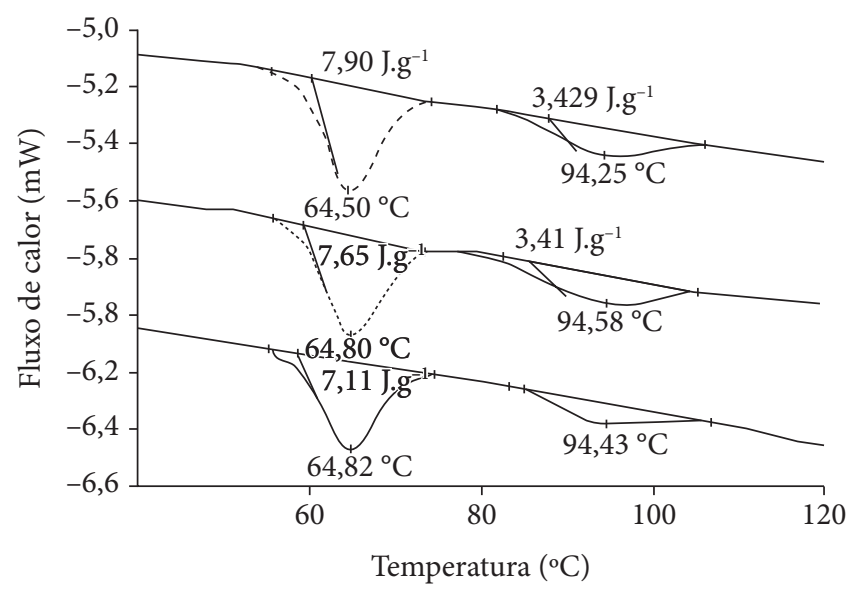

Figura 5. Termogramas (triplicatas) do amido de aveia. 


\section{Conclusões}

A presença do alto teor de lipídios (1,36\%) no amido de aveia e também seu alto grau de complexação com a amilose fazem com que este amido apresente comportamento diferenciado em relação ao de outros cereais. Sua alta estabilidade à retrogradação sugere aplicação como espessante em produtos refrigerados. A baixa Tg do amido de aveia indicou uma estrutura cristalina menos organizada devido provavelmente à presença dos lipídios. Pastas de amido de aveia mostraram comportamento reofluidizante, isto é, a viscosidade decresceu com o aumento da taxa de cisalhamento.

\section{Agradecimentos}

Os autores agradecem o suporte financeiro fornecido à CAPES (ProDoc), CyTED e SETI -PR (Brasil) e à indústria SL Alimentos (Mauá da Serra, Paraná) a liberação da autora Melicia C. Galdeano para a execução do trabalho.

\section{Referências bibliográficas}

AMERICAN ASSOCIATION OF CEREAL CHEMISTS - AACC. Approved methods of the American Association of Cereal Chemists. 8 ed. St. Paul: Minnesota, 1990.

BILIADERIS, C. G. Structures and phase transitions of starch in food systems. Food Technology, v. 46, n. 6, p. 98-109, 1992.

CEREDA, M. P. Propriedades do amido. In: CEREDA, M. P.; VILPOUX, $O$. Culturas de tuberosas amiláceas latino americanas: tecnologia, usos e potencialidades de tuberosas amiláceas Latino Americana. São Paulo: Fundação Cargill, 2003. p. 141-185. (v. 1).

CHUNG, Y. L.; LAI, H. M. Water-Barrier property of starch films investigated by magnetic resonance imaging. Cereal Chemistry, v. 82, n. 2, p. 131-137, 2005.

DELLA-VALLE, D. G. Estudios reológicos y térmicos del almidón de plátano (Musa paradisiaca) modificado por acetilación y oxidación. Acapulco, 2005. 92 p. Monografia (Graduação em Alimentos) - Instituto Tecnológico de Acapulco.

DOUBLIER, J. L.; PATON, D.; LLAMAS, G. A rheological investigation of oat starch pastes. Cereal Chemistry, v. 64, n. 1, p. 21-26, 1987.

ELIASSON, A. C. Starch in food: structure, function and applications. New York: CRC Press, 2004.

FENNEMA, O. R. Química de los alimentos. Zaragoza: Acribia, 1993.

FRANCISCO, A. et al. Estudo comparativo de cultivares de aveia (Avena sativa L.) do sul do Brasil: efeito da morfologia do grão no rendimento industrial. Acta Científica Venezolana, v. 53, n. 3 , p. 195-201, 2002.

HOOVER, R. et al. Physicochemical properties of Canadian oat starches. Carbohydrate Polymers, v. 52, n. 1, p. 253-261, 2003.

HOOVER, R. et al. The effects of defatting and heat-moiture treatment on the retrogradation of starch gels from wheat, oat, potato and lentil. Carbohydrate Research, v. 29, n. 1, p. 15-26, 1994.
HOOVER, R.; SENANAYAKE, S. P. J. N. Composition and physicochemical properties of oat starches. Food Research International, v. 29, n. 1, p. 15-26, 1996.

JARVIS, C. E.; WALKER, J. R. L. Simultaneous, rapid, spectrophotmetric determination of total starch, amylose and amylopectin. Journal Science Food Agriculture, v. 63, n. 1, p. 53-57, 1993.

KARAM, L. B. Propriedades funcionais de multi-misturas de amido de milho, mandioca e cará e sua relação com as características físicas e moleculares. Londrina, 2003. 190 p. Tese (Doutorado em Ciência de Alimentos) - Universidade Estadual de Londrina - UEL.

LANDERS, P. S.; GBUR, E. E.; SHARP, R. N. Comparison of two models to predict amylose concetration in rice flours as determined by spetrophotometric assay. Cereal Chemistry, v. 68, n. 5, p. 545-548, 1991.

LIM, W. J. et al. Isolation of oat starch from oat flour. Cereal Chemistry, v. 69, n. 3, p. 233-236, 1992.

MacARTHUR, A.; D'APPOLONIA, B. L. Comparison of oat and wheat carbohydrates. Cereal Chemistry, v. 56, n. 5, p. 458-461, 1979. (v. II, Starch).

MALI, S. et al. Effects of controlled storage on thermal, mechanical and barrier properties of plasticized films from different starch sources. Journal of Food Engineering, v. 75, n. 4, p. 453-460, 2006.

MUA, J. P.; JACKSON, D. S. Gelatinization and solubility properties of commercial Oat Starch. Starch, v. 47, n. 1, p. 2-7, 1995.

PAREDES-LÓPEZ, O.; BELLO-PÉREZ, L. A.; LÓPEZ, M. G. Amylopectin: structural, gelatinization and retrogradación studies. Food Chemistry, v. 50, n. 4, p. 411-418, 1994.

SHAMEKH, S.; FORSSELL, P.; POUTANEN, K. Solubility pattern and recrystallization behavior of oat starch. Starch, v. 46, n. 4 , p. 129-133, 1994.

SOPADE, P. A.; HALLEY, P. J.; JUNMING, L. L. Gelatinization of starch in mixture of sugars. I Dynamic rheological properties and behaviours of starch-honey systems. Journal of Food Engineering, v. 61, n. 3 , p. $439-448,2004$.

STEFFE, J. F. Rheological methods in food process engineering. 2 ed. East Lansing: Freeman Press, 1996.

TANG, H.; WATANATBE, K.; MITSUNAGA, T. Characterization of storage starches from quinoa, barley and adzuki seeds. Carbohydrate Polymers, v. 49, n. 1, p. 13-22, 2002.

VASANTHAN, T.; HOOVER, R. A comparative study of the composition of lipids associated with starch granules from various botanical sources. Food Chemistry, v. 43, n. 1, p. 19-27, 1992.

WANG, L. Z.; WHITE, P. J. Functional properties of oats starches and relationships among functional and structural characteristics. Cereal Chemistry, v. 71, n. 5, p. 451-458, 1994c.

WANG, L. Z.; WHITE, P. J. Structure and physicochemical properties of starches from oats with different lipid contents. Cereal Chemistry, v. 71, n. 5, p. 443-450, 1994 b.

WANG, L. Z.; WHITE, P. J. Structure and properties of amylose, amylopectin, and intermediate materials of oats starch. Cereal Chemistry, v. 71, n. 3, p. 263-268, 1994a.

ZHOU, M. et al. Structure and pasting properties of oat starch. Cereal Chemistry, v. 75, n. 3, p. 273-281, 1998. 